University of Nebraska - Lincoln

DigitalCommons@University of Nebraska - Lincoln

September 1994

\title{
Novel methods for the fabrication of ferromagnetic nickel and nickel boride thin films
}

D. Zych

SUNY-Oswego

A. Patwa

SUNY-Oswego

S.S. Kher

Syracuse University

N.M. Boag

Syracuse University

Peter A. Dowben

University of Nebraska-Lincoln, pdowben@unl.edu

Follow this and additional works at: https://digitalcommons.unl.edu/physicsdowben

Part of the Physics Commons

Zych, D.; Patwa, A.; Kher, S.S.; Boag, N.M.; and Dowben, Peter A., "Novel methods for the fabrication of ferromagnetic nickel and nickel boride thin films" (1994). Peter Dowben Publications. 54.

https://digitalcommons.unl.edu/physicsdowben/54

This Article is brought to you for free and open access by the Research Papers in Physics and Astronomy at DigitalCommons@University of Nebraska - Lincoln. It has been accepted for inclusion in Peter Dowben Publications by an authorized administrator of DigitalCommons@University of Nebraska - Lincoln. 


\title{
Novel methods for the fabrication of ferromagnetic nickel and nickel boride thin films
}

\author{
D. Zych and A. Patwa \\ Department of Physics, SUNY-Oswego, Oswego, New York 13126
}

S. S. Kher, J. T. Spencer, and J. Kushneir

The W. M. Keck Center for Molecular Electronics and the Departments of Chemistry and Physics, Syracuse University, Syracuse, New_ York 13244

A. J. Goodby and N. M. Boag

Division of Chemical Sciences, Science Research Institute, Salford M5 4WT, United Kingdom

P. A. Dowben a)

Department of Physics, Behlen Laboratory of Physics, University of Nebraska-Lincoln, Lincoln, Nebraska 68588-0111

(Received 18 February 1994; accepted for publication 25 May 1994)

\begin{abstract}
Metal-rich nickel boride thin films fabricated from boron-containing precursor compounds by a cluster deposition process are shown to be ferromagnetic. The metal-rich films fabricated by this approach exhibit hysteresis curves similar to those obtained for pure nickel foils. These films are a mixture of pure nickel and the $\mathrm{Ni}_{3} \mathrm{~B}$ nickel boride phases. It is postulated that the hysteresis curves with smaller remnant magnetizations obtained from these films are a consequence of $\mathrm{Ni}_{3} \mathrm{~B}$ inclusions within the films. Other novel organometallic source compounds for nickel chemical-vapor deposition are briefly reviewed.
\end{abstract}

\section{INTRODUCTION}

There has been considerable interest in the magnetic properties of Ni-B alloys which has been driven in part by the unusual properties of some of these alloys. ${ }^{1-9}$ Particularly interesting are the materials whose compositions are close to the eutectic point of about $18 \%$ boron. Films of such alloys have been fabricated by a wide variety of techniques including physical-vapor deposition, ${ }^{10}$ rapid quenching, ${ }^{4,5,7,8,11-13}$ and chemical reduction. ${ }^{14}$ Only recently have nickel-boron alloy films been made by chemical-vapor deposition (CVD). ${ }^{15-17}$

There have been basically two approaches to the chemical-vapor deposition of nickel-boron alloy films. One approach involves the pyrolytic CVD of gaseous mixtures of nickel tetracarbonyl, $\mathrm{Ni}(\mathrm{CO})_{4}$ and diborane, $\mathrm{B}_{2} \mathrm{H}_{6} \cdot{ }^{18,19}$ The expense, toxicity, and nature of these reagents presents serious disadvantages to this approach. Unfortunately, only a limited number of organometallic nickel source compounds have been considered for CVD. ${ }^{20.21}$ The other approach has employed a boron polyhedral cluster-assisted deposition process ${ }^{15-17}$ where a vapor-phase reaction of the boron cluster with anhydrous nickel chloride $\left(\mathrm{NiCl}_{2}\right)$ was used to deposit nickel borides in a hot-walled vacuum deposition system. It was the latter CVD deposition approach that was employed in this work.

\section{EXPERIMENT}

The cluster-assisted depositions were carried out, as previously described, ${ }^{15}$ in a vacuum hot-wall deposition apparatus $\left(1 \times 10^{-6}\right.$ Torr $)$ equipped with a chromel-alumel thermo-

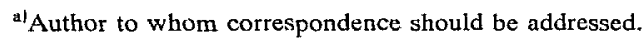

couple. A boron source reservoir containing either freshly sublimed nido-pentaborane- $9, \mathrm{~B}_{5} \mathrm{H}_{9}$, or nido-decaborane-14, $\mathrm{B}_{10} \mathrm{H}_{14}$, was connected to the reactor. The reservoir was maintained at constant temperature $\left(22^{\circ} \mathrm{C}\right.$ for decaborane and $-78^{\circ} \mathrm{C}$ for pentaborane) and borane vapor was passed over hot anhydrous $\mathrm{NiCl}_{2}$ in the reactor vessel.

The resulting films were analyzed by a variety of techniques including Auger electron spectroscopy (AES), scanning electron microscopy (SEM), $x$-ray emission spectroscopy (XES), $x$-ray thin-film diffraction (XRD), vibrating sample magnetometry, and atomic absorption elemental analysis.

The photolytic deposition of nickel was carried out as described elsewhere. ${ }^{22,23}$ A nitrogen laser was used to illuminate silicon, gold, and Kapton (polyimide plastic) substrates in an array of $20 \times 20 \mu \mathrm{m}$ squares using a close contact mask during $\mathrm{Ni}\left(\eta^{5}-\mathrm{C}_{5} \mathrm{Me}_{5}\right)\left(\eta^{3}-\mathrm{C}_{3} \mathrm{H}_{5}\right)$ exposure.

The anion $\left[\mathrm{Ni}\left(\eta^{5}-\mathrm{C}_{5} \mathrm{Me}_{5}\right)(\mathrm{CO})\right]^{-}$was prepared by treatment of a THF solution of $\mathrm{Ni}_{2}\left(\eta^{5}-\mathrm{C}_{5} \mathrm{Me}_{5}\right)_{2}(\mathrm{CO})_{2}$ (Ref. 24) with sodium-potassium alloy. This solution was filtered through celite into allyl chloride. In over $10 \mathrm{~min}$ the reaction mixture turned purple. The solution was evaporated to dryness in vacuo and the product sublimed at room temperature under vacuum $(0.1 \mathrm{~mm} \mathrm{Hg})$ leading to purple waxy crystals of $\mathrm{Ni}\left(\eta^{5}-\mathrm{C}_{5} \mathrm{Me}_{5}\right)\left(\eta^{3}-\mathrm{C}_{3} \mathrm{H}_{5}\right) \quad[60 \%$ from $\left.\mathrm{Ni}_{2}\left(\eta^{5}-\mathrm{C}_{5} \mathrm{Me}_{5}\right)_{2}(\mathrm{CO})_{2}\right]$. Spectral data were in agreement with literature values. ${ }^{25}$ By nuclear magnetic resonance (NMR) (JEOL EX 90): ${ }^{13} \mathrm{C}\left\{{ }^{1} \mathrm{H}\right\}\left(d^{6}\right.$-benzene) was $98.1\left(s, \mathrm{CCH}_{3}\right), 93.2(s, \mathrm{CH}), 42.1 \quad\left(s, \mathrm{CH}_{2}\right), 10.6$ $\left(s, \mathrm{CCH}_{3}\right) ;{ }^{1} \mathrm{H}\left(d^{6}\right.$-benzene) it was 5.09 ( $t$ of $t, 1 \mathrm{H}, \mathrm{CH}$, $\left.J_{\mathrm{HH}}-6.15 \mathrm{~Hz}, J_{\mathrm{HH}}=10.55 \mathrm{~Hz}\right), 2.08(d, 2 \mathrm{H}, \mathrm{H}(\mathrm{syn})$ $J_{\mathrm{HH}}=6.15 \mathrm{~Hz}, 1.84\left(s, 15 \mathrm{H}, \mathrm{CCH}_{3}\right), 1.18[d, 2 \mathrm{H}, \mathrm{H}$ (anti), $\left.J_{\mathrm{HH}}=10.55 \mathrm{~Hz}\right]$. 


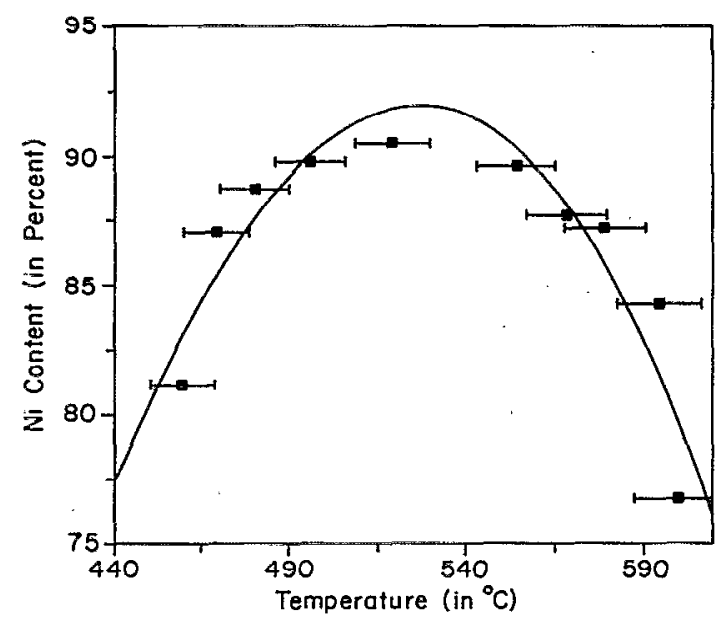

FIG. 1. Plot of the nickel content vs the deposition temperature for nickel boride thin films as determined by atomic absorption elemental analysis (error bars indicate $2 \%$ of the coordinate). The films were prepared on a quartz substrate using a nido-pentaborane, $\mathbf{B}_{5} \mathrm{H}_{4}$, borane source kept at $-78^{\circ} \mathrm{C}$ during the deposition.

\section{COMPOSITION AND MORPHOLOGY}

There exists a relationship between the reactor temperature (deposition temperature) and composition (as noted previously ${ }^{15}$ ) for the cluster-assisted deposition of nickel borides. For a constant $\mathrm{B}_{5} \mathrm{H}_{9}$ flow rate, the relationship between deposition temperature and nickel content in the film is shown in Fig. 1. The composition of the film was determined by atomic absorption elemental analysis. Both XES and AES results confirm the presence of large nickel content in these films and an absence of contamination in the film. For example, no chloride contamination was found. A Fourier transform infrared (FTIR) spectrum of a ground film fabricated by this tcchnique showed no evidence of $\mathrm{B}-\mathrm{H}$ vibrations (typically near $2500 \mathrm{~cm}^{-1}$ ) confirming the absence of intact borane clusters or cluster fragments trapped within the film.

Scanning electron microscopy (SEM) provided evidence that the films formed by cluster-assisted deposition suffer only from small surface voids of the order of $1 \mu \mathrm{m}$ scale. ${ }^{15}$ XRD studies of both the as-deposited and annealed films (Fig. 2), show that all the films are polycrystalline. The unannealed films were found to contain primarily pure nickel crystallites with small amounts of $\mathrm{Ni}_{3} \mathrm{~B}$ crystallites within the film. Annealing the film lead to a decrease in the $\mathrm{Ni}_{3} \mathrm{~B}$ phase relative to the nickel phase, as well as the growth of $\mathrm{Ni}_{7} \mathrm{~B}_{3}$ hexagonal crystallites as observed in XRD and SEM. ${ }^{15}$

Takahashi and co-workers ${ }^{8}$ found that their Ni-B "amorphous" alloys contained a substantial number of Ni-phase and $\mathrm{Ni}_{3} \mathrm{~B}$-phase crystallites. Bakonyi and co-workers ${ }^{6}$ attributed the ferromagnetic contribution that they and others observed in $18 \% \mathrm{~B}$ amorphous Ni-B alloys to magnetic crystallites. We also find that the magnetization is dominated by the crystallite contributions to the film.

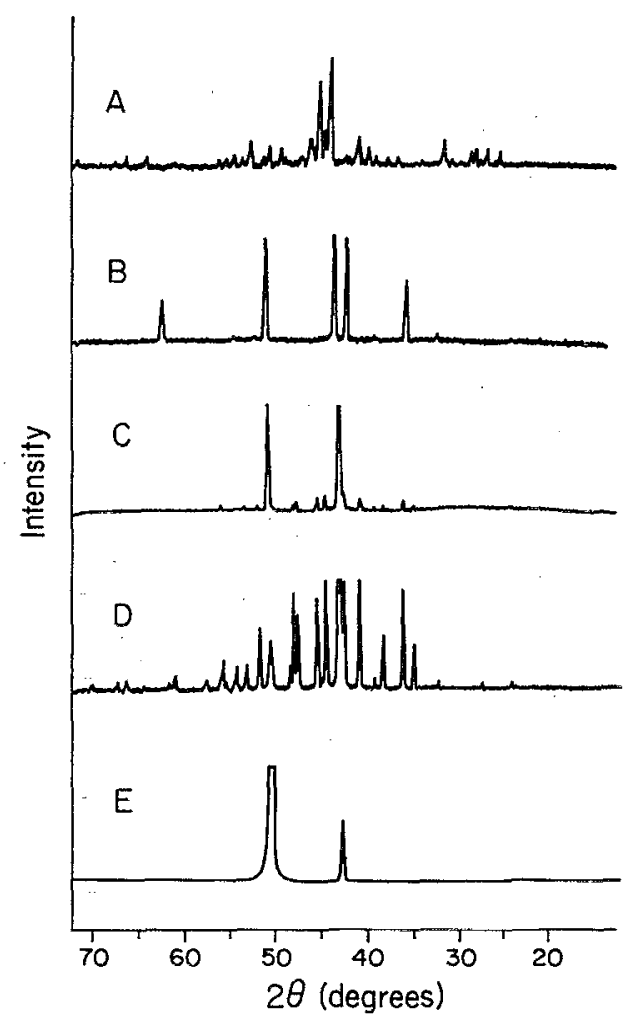

FIG. 2. X-ray-diffraction spectra for nickel boride thin films deposited on fused silica (quartz) from $\mathrm{NiCl}_{2}$ and nido- $\mathrm{B}_{5} \mathrm{H}_{9}$. The XRD spectra were recorded at room temperature from free-standing films mounted on Pyrex plates. The largest peak in each spectrum is cropped in order to display the smaller peaks in each spectrum. (a) Diffractogram of a boron-rich thin film deposited at $502{ }^{\circ} \mathrm{C}$ and annealed at $830^{\circ} \mathrm{C}$ for $38 \mathrm{~h}$ postdeposition. (b) Diftractogram of nickel-rich thin film deposited at $482^{\circ} \mathrm{C}$ and annealed at $750^{\circ} \mathrm{C}$ for $15 \mathrm{~h}$ postdeposition. This diffractogram is essentially identical to that of commercially obtained pure nickel foil (Aldrich) that had been similarly annealed. (c) Diffractogram of an as-deposited nickel-rich thin film deposited at $482^{\circ} \mathrm{C}$. The diffractogram clearly shows the presence of both pure nickel and the $\mathrm{Ni}_{3} \mathrm{~B}$ nickel boride phase. (d) Diffractogram of a commercially obtained $\mathrm{Ni}_{3} \mathrm{~B}$ powder (Cerac). (e) Diffractogram of a commercially obtained pure nickel foil (Aldrich).

\section{MAGNETIZATION}

The room-temperature magnetization of cluster-assisted deposited films of nickel boride is about $2.0 \times 10^{5}$ to $2.8 \times 10^{5}$ $\mathrm{A} / \mathrm{m}$, with an average of about $2.3 \times 10^{5} \mathrm{~A} / \mathrm{m}\left(230 \mathrm{emu} / \mathrm{cm}^{3}\right)$ for samples containing between $10 \%$ and $18 \%$ boron that were made with pentaborane. This magnetization is about half that expected for bulk nickel $\left(487 \mathrm{emu} / \mathrm{cm}^{3}\right)$, as seen from Fig. 3.

Films made from decaborane, by the cluster-assisted deposition process, were somewhat more boron rich (slightly more than $20 \%$ ). These films had smaller saturation magnetizations ranging from $1.2 \times 10^{5}$ to $1.4 \times 10^{5} \mathrm{~A} / \mathrm{m}$ with an average of about $1.3 \times 10^{5} \mathrm{~A} / \mathrm{m}\left(130 \mathrm{emu} / \mathrm{cm}^{3}\right)$ as seen in Fig. 3 . Qualitatively, the hysteresis loop for these films fabricated with decaborane resembles the hysteresis curve obtained from nickel foil except for a remanence closer to $27 \%$ as compared with about $50 \%$ for nickel. The remanences for the films fabricated with pentaborane were higher at about $33 \%$. than for those fabricated with decaborane. Qualitatively, both 


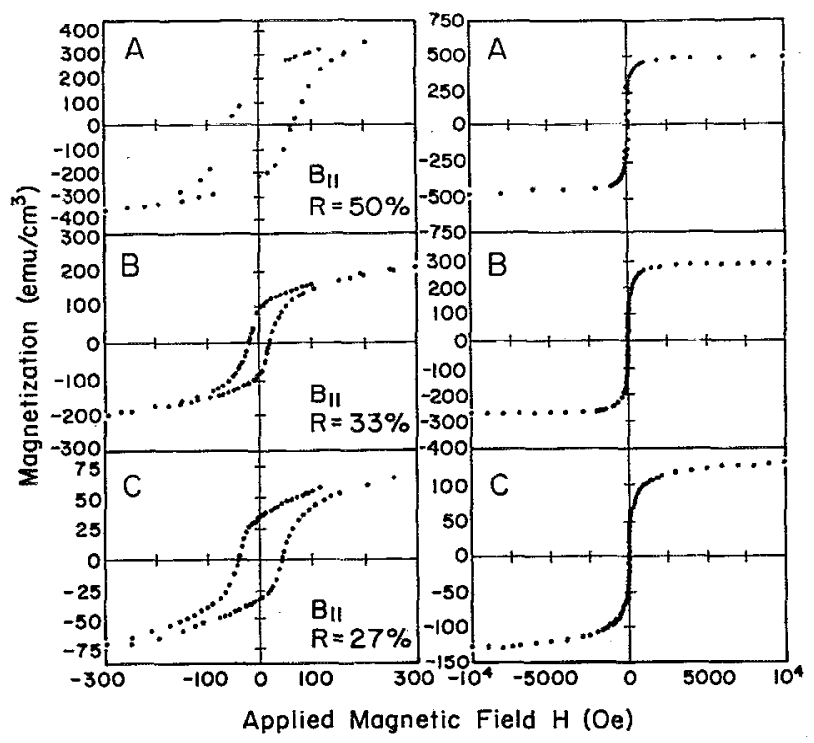

FIG. 3. The vibrating sample magnetrometry of (A) a pure nickel foil and cluster-assisted Ni-B films fabricated with (B) pentaborane and (C) decaborane cluster sources. The magnetization is at room temperature and in plane throughout. Demagnetization factors for these samples were measured to be much less than 0.1 .

types of films are more difficult to saturate as compared to pure nickel. The differences in remanences could be a consequence of the fact that the film made from decaborane has greater compositional anisotropy within the film and/or considerably more compositional defects that pin the magnetization.

The hysteresis loops strongly suggest that the ferromagnetic properties of the films are dominated by the nickel crystallites. Reduction of the saturation magnetization and coercivity due to the paramagnetic $\mathrm{Ni}_{3} \mathrm{~B}$ phase is not unexpected. The coercivities for the Ni-B films fabricated with pentaborane are consistently about half $(20 \mathrm{Oe})$ the coercivity of the film made with decaborane (40-45 Oe), resulting in a narrower hysteresis loop. We cannot explain this reduction but again it may be an absence of compositional uniformity (bigger crystallites) in the films made with decaborane. The shapes of the hysteresis curves for the Ni-B film made with pentaborane suggests that the easy axis of magnetization is "in plane."

It has been reported that Ni-B films may have some magnetic anisotropy. ${ }^{5,6}$ Measurements of the magnetoresistance of a film made with pentaborane at $4.2 \mathrm{~K}$ indicate only a $1.1 \%$ increase in the resistance at $1 \mathrm{~T}$ for fields perpendicular to the plane of the film, as seen in Fig. 4. For parallel fields, the magnetoresistance effect is $34 \%$ higher than for perpendicular fields, demonstrating no marked anisotropy. These effects are approximately what one obtains from bulk nickel (upper curve in Fig. 4) after accounting for the differences in the residual resistances. This supports our conclusion that the ferromagnetic properties of these films are dominated by nickel crystallites (composing some $30 \%$ of the film or more.) The magnetoresistance data does not indicate an easy axis of magnetization as being in plane. Given

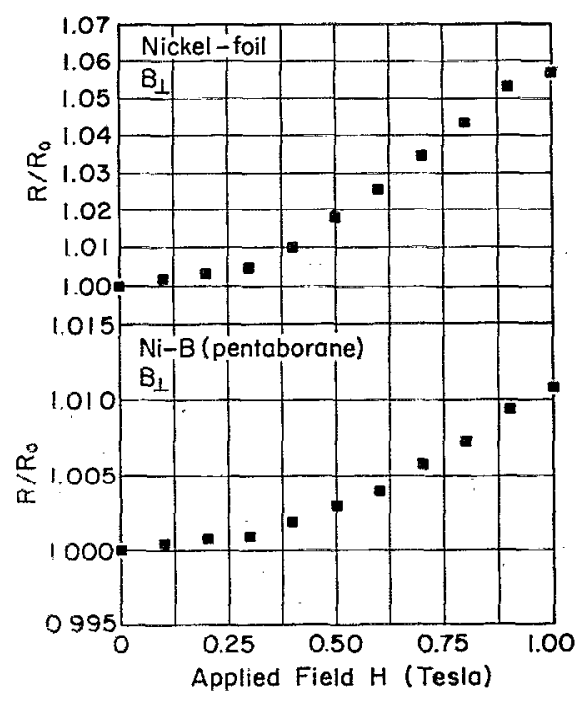

FIG. 4. (Top) For comparison, the magnetoresistance of bulk nickel is shown for fields perpendicular to the sample current. An 18\% increase in resistance was observed at $1 \mathrm{~T}$ when the field was rotated parallel to the current. (Bottom) The planar magnetoresistance of $\mathrm{Ni}_{87} \mathrm{~B}_{13}$ at $4.2 \mathrm{~K}$ with the magnetic field perpendicular to the film. In-plane magnetoresistance for this sample was slightly larger (34\% at $1 \mathrm{~T}$ ) than for perpendicular fields.

that the thickness of these films is close to $1 \mu \mathrm{m}$ we cannot assign the direction of the easy axis of magnetization, despite the apparent in-plane easy axis of magnetization in the hysteresis curve data.

Also supporting this conclusion are measurements of the temperature dependence of the saturation magnetization (data not shown) of both the pentaborane and decaborane films. The spin-wave coefficients for both films are approximately the same as those for pure nickel. This suggests little or no change in the magnon dispersion relation for the $\mathrm{Ni}-\mathrm{B}$ films as compared with nickel.

\section{OTHER DEPOSITION METHODS}

While the cluster-assisted deposition procedure above does lead to the deposition of ferromagnetic nickel boride films, other novel chemical-vapor-deposition techniques for the deposition of nickel and nickel boride do exist and show some promise. From the beginning, studies of the organometallic chemical-vapor deposition of nickel (OMCVD) favored the commercially available binary metal carbony complexes $\left[\mathrm{Ni}(\mathrm{CO})_{4}\right]$ as $\mathrm{CVD}$ sources. These species are already in the zerovalent state and it was felt that the carbonyl groups would be readily lost on thermolysis (pyrolysis) or photolysis as has been demonstrated through simple substitution chemistry in solution. Furthermore, Mond has demonstrated in the last century that the reversible reaction of nickel with carbon monoxide affords an excellent method for the production of pure nickel, a process still used industrially today,

$$
\mathrm{Ni}(\text { impure })+4 \mathrm{CO} \rightarrow \text { volatile } \mathrm{NI}(\mathrm{CO})_{4} \rightarrow \mathrm{Ni}(\text { pure })+4 \mathrm{CO} \text {. }
$$

However, the deposition of thin films is a complex process $^{20}$ involving reactivity both in the gas phase and at the surface, and $\mathrm{Ni}(\mathrm{CO})_{4}$ is not always suitable as a source compound. 

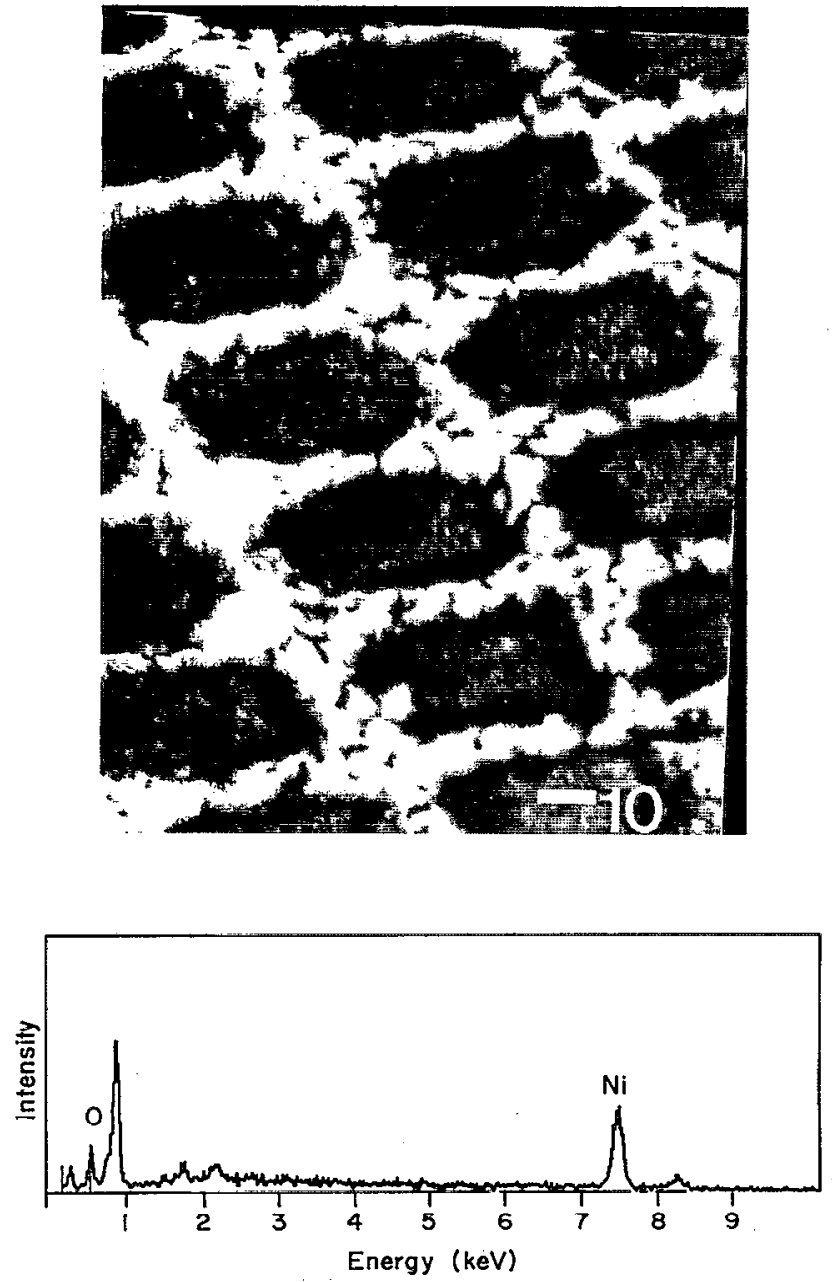

FIG. 5. (Top) A scanning electron microscope picture of $20 \times 20 \mu \mathrm{m}^{2}$ nickel squares deposited on $\mathrm{Si}(111)$ from the photolysis of $\mathrm{Ni}\left(\eta^{5}-\mathrm{O}_{5} \mathrm{Me}_{5}\right)\left(\eta^{3}-\mathrm{C}_{3} \mathrm{H}_{5}\right)$. The bar denotes $10 \mu \mathrm{m}$. (Bottom) The $\mathrm{x}$-ray emission spectra (XES or EDAX) of the film showing the presence of nickel in the film. The incident electron energy is $14 \mathrm{keV}$. The oxygen signal is a result of postdeposition exposure to air.

Other source compounds, beyond the readily available $\mathrm{Ni}(\mathrm{CO})_{4}$, have been tried for CVD. Nickclocene, $\mathrm{Ni}\left(\eta^{5}-\mathrm{C}_{5} \mathrm{H}_{5}\right)_{2}$, has been used for the pyrolytic and photolytic deposition of nickel. ${ }^{20-23}$

Source compounds more volatile but less stable than nickelocene are available. We deposited nickel from $\mathrm{Ni}\left(\mathrm{C}_{5} \mathrm{Me}_{5}\right)\left(\eta^{3}-\mathrm{C}_{5} \mathrm{H}_{5}\right)$ by photolysis using UV radiation from a nitrogen laser $(337 \mathrm{~nm})$. This compound is more volatile than nickelocene but air sensitive. As seen in Fig. 5, the spatially selective deposition of nickel is possible from this source compound. As with other studics ${ }^{21-22}$ the selective area deposition was undertaken by imaging the UV light on the substrate through a close contact mask. This extremely selective deposition tends to suggest the decomposition is indeed surface mediated.

For the fabrication of stoichometric metal borides a polymer precursor route holds considerable promise. ${ }^{26}$

\section{ACKNOWLEDGMENTS}

This work was supported by the NSF through Grant No. DMR-92-21655. Additional support was provided by Leybold Inficon, the Center for Materials Research and Analysis, the W. M. Keck Foundation through the W. M. Keck Center for Molecular Electronics, and the State University of New York. We thank the SERC for a studentship (A. J. G.)

'M. Takahashi and F. Sato, J. Magn. Magn. Mater. 15-18, 1407 (1980).

${ }^{2}$ I. W. Donald and H. A. Davies, J. Mater. Sci. 15, 2754 (1980).

${ }^{3}$ S. N. Kaul and M. Rosenberg, Phys. Rev. B 25, 586 (1982).

${ }^{4}$ R. Motsay, L. Q. Wang, D. G. Onn, I. W. Donald, and H. A. Davies, J. Appl. Phys. 53, 7774 (1982).

${ }^{5}$ I. Bakonyi, P. Panissod, J. Durand, and R. Hasegawa, J. Non-Cryst. Solids 61/62, 1189 (1984).

"I. Bakonyi, P. Pannissod, and R. Hasegawa, J. Appl. Phys. 53, 7771 (1982).

${ }^{7}$ M. Takahashi, C. O. Kim, M. Koshimura, and T. Suzuki, Jpn. J. Appl. Phys. 17, 741 (1978).

${ }^{8}$ M. Takahashi, Y. Tateno, and M. Koshimura, Jpn. J. Appl. Phys. 19, 2335 (1980).

${ }^{9}$ W. A. Hines, C. U. Modzelewski, R. N. Paolino, and R. Hasegawa, Solid State. Commun. 39, 699 (1981).

${ }^{10}$ A. G. Dirks and J. R. M. Gijsbers, J. Phys. D 12, 149 (1979).

"Y. Waseda and H. S. Chen, Phys. Status Solidi A 49, 387 (1978).

${ }^{12}$ I. W. Donald and H. A. Davies, J, Mater. Sci. 15, 2754 (1980).

${ }^{13} \mathrm{H}$. H. Liebermann and J. Wong, J. Non-Cryst. Solids 45, 195 (1981).

${ }^{14}$ T. Watanabe and Y. Tanabe, Mater. Sci. Eng. 23, 97 (1976).

${ }^{15}$ S. S. Kher and J. T. Spencer, Chem. Mater. 4, 538 (1992).

${ }^{16}$ 7. Thang, Y.-G. Kim, P. A. Dowben, and J. T. Spencer, Mater. Res. Soc. Symp. Proc. 131, 401 (1989).

${ }^{17}$ J. A. Glass, Jr., S. Kher. Y.-G. Kim, P. A. Dowben, and J. T. Spencer, Mater. Res. Soc. Symp. Proc. 204, 439 (1991).

${ }^{18}$ A. W. Mullendore and L. E. Pope, Thin Solid Films 153, 267 (1987).

${ }^{19}$ M. Skibo and F. A. Greulich, Thin Solid Films 113, 225 (1984).

${ }^{20}$ P. A. Dowben, J. T. Spencer, and G. T. Stauf, Mater. Sci. Eng. B 2, 297 (1989); N. M. Boag and P. A. Dowben, in Metallized Plastics IV: Fundamental and Applied Aspects, edited by K. Mittal (Plenum, New York).

${ }^{21}$ G. Stauf, D. C. Driscoll, P. A. Dowben, S. Barfuss, and M. Grade, Thin Solid Films 153, 421 (1987).

${ }^{22}$ G. T. Stauf and P. A. Dowben, Thin Solid Films 156, L31 (1988).

${ }^{2.3}$ Y.-G. Kim, D. Byun, C. Hutchings, P. A. Dowben, H. Hejase, and K. Schröder, J. Appl. Phys. 70, 6062 (1991).

${ }^{24}$ N. M. Boag, A. J. Goodby, and R. Quyoum, Organometallics 11, 3135 (1992).

${ }^{25}$ H. Lehmkuhl, J. Näser, G. Mehler, T. Keil, F. Danowski, R. Benn, R. Mynott, G. Schroth, B. Gabor, C. Krïger, and P. Betz, Chem. Ber. 124, 441 (1991).

${ }^{26}$ K. Su and L. G. Sneddon, Chem. Mater. 5, 1659 (1993). 